\title{
Determination Composition of Anthocyanins in Black Chokeberry, Serviceberry and Blue-Berried Honeysuckle with HPLC
}

\author{
Svetlana A. Polina and Alexander A. Efremov* \\ Siberian Federal University \\ 79 Svobodny, Krasnoyarsk, 660041 Russia
}

Received 23.01.2015, received in revised form 11.02.2015, accepted 28.03.2015

The article contains information about anthocyanin composition of frozen fetuses of black chokeberry (Aronia melanocarpa), serviceberry (Amelanchier ovalis Medik), blue-berried honeysuckle (Lonicera caerulea L) which grow in Yenisei district of the Krasnoyarsk krai. Determination composition of anthocyanins of berries by HPLC with UV detection. Comparative analysis of the qualitative composition and quantitative content of anthocyanin.

Keywords: Aronia melanocarpa, Amelanchier ovalis Medik., Lonicera caerulea L, extract, cyanidin3-galactoside, cyanidin-3-glucoside, anthocyanins, HPLC.

\section{Состав антоцианов плодов рябины черноплодной, ирги овальнолистной и жимолости голубой Сибирского региона по данным ВЭЖХ}

С.А. Полина, А.А. Ефремов

Сибирский федеральный университет Россия, 660041, Красноярск, пр. Свободный, 79

B статье приведены данные об антоичановом составе мороженых плодов рябины черноплодной (Aronia melanocarpa), ирги овальнолистной (Amelanchier ovalis Medik.), жимолости голубой (Lonicera caerulea L), собранных на территории Енисейского района Красноярского края. Методом ВЭЖХ с УФ-детектированием определён антоциановый

(C) Siberian Federal University. All rights reserved

* Corresponding author E-mail address: AEfremov@sfu-kras.ru 
состав данных ягод. Проведено сравнение качественного состава и количественного содержание антоцианов.

Ключевые слова: Aronia melanocarpa, Amelanchier ovalis Medik., Lonicera caerulea L, циианидин3-галактозид, ичианидин-3-глюкозид, антоцианы, экстракт, ВЭЖХ.

\section{Введение}

В настоящее время научной медициной недостаточно широко используются многие лекарственные растения, так как являются малоизученными. При этом фармацевтическая практика постоянно требует увеличения ассортимента и количества лекарственного растительного сырья. Это особенно актуально для регионов, удалённых от Центральной России: Восточной Сибири, Якутии и Дальнего Востока [1].

Антоцианы (от греч. anthos - цветок и kyanos - синий, лазоревый) являются самой крупной группой водорастворимых пигментов в царстве растений [2]. Они принадлежат к большой и широко распространенной группе веществ, содержащихся в растениях, флавоноидам [3].

Качественный состав антоцианов, как правило, специфичен для конкретного вида растений и довольно стабилен [4]. Однако он зависит от особенностей и условий произрастания растения [5].

Черноплодная рябина - растение семейства розоцветных, плоды которой используются в пищевых и медицинских целях. Густая темно-фиолетовая окраска плодов аронии свидетельствует о высоком содержании в них антоциановых соединений [6]. Суммарное содержание антоциановых пигментов в зрелых плодах доходит до 6,4 \% [7]. Японские учёные обнаружили в рябине цианидин, который присутствует в виде четырёх соединений: цианидин-3-галактозид и цианидин-3-арабинозид, цианидин-3-глюкозид, цианидин-3-ксилозид [8]. Учёные из США установили, что цианидин-3-глюкозид обладает антиканцерогенными свойствами [9].

Обилие витамина Р позволяет рекомендовать плоды ирги овальнолистной и соки из них пожилым людям для укрепления стенок сосудов и повышения их эластичности, предупреждения инфаркта миокарда и варикозного расширения вен. Плоды ирги - хорошее поливитаминное средство, их применяют для лечения гипо- и авитаминозов [10]. В ирге много флавоноидов, среди которых преобладают лейкоантоцианы и антоцианы, по количеству которых (1080 мг на 100 г) ирга не уступает чёрной смородине и вишне. Эти вещества обладают капилляроукрепляющими, противосклеротическими и противоспалительными свойствами. Созревающие плоды Amelanchier обязаны своей окраской антоцианам, по мере образования антоцианов они изменяют свой цвет [11]. Установлено, что в шести исследованных видах ирги основными компонентами являются цианидин-3-галактозид, в меньших количествах содержатся цианидин-3-глюкозид и цианидин-3-арабинозид. Высокое содержание антоцианов позволяет использовать плоды ирги в качестве естественного пищевого красителя [12].

Тёмно-синяя окраска плодов жимолости обусловлена накоплением антоцианов, внимание к которым привлечено благодаря широкому спектру биологической активности этих соединений [13]. Содержание антоцианов в некоторых сортах жимолости достигает до 400-450 мг/100 г ягод, благодаря чему жимолость можно отнести к богатым источникам этих соединений и пер- 
спективным материалам для выделения антоциановых пигментов. В экстрактах жимолости обнаруживается один основной компонент - цианидин-3-глюкозид, доля которого в сумме антоцианов по площадям пиков в ряде случаев превышает 85 \%. Заметно меньше содержание цианидин-3-рутинозида и аналогичных производных пеларгонидина (Pg-3-glu) и пеонидина (Pn-3-glu и Pn-3-Rut), обнаруживаются также цианидин-3,5-диглюкозид (Су-3,5-diGlu). Это принципиально соответствует литературным данным: в работе польских исследователей исследованы Cyn-3-glu, Cyn-3-rut, Cyn-3,5-diGlu, Pn-3-rut, а в работе исследователей из США к этому списку добавлены Pg-3-glu и Pn-3-rut. Анализируя полученные в настоящей работе и литературные данные, можно сделать вывод о постоянстве качественного состава антоцианов синеплодных видов и сортов жимолости, которые могут рассматриваться как источник вещества - «свидетеля» - цианидина-3-глюкозида для идентификации антоцианов в сложных смесях [14].

Известно, что состав БАВ и уровень их накопления зависит от почвенно-климатических условий их произрастания. Поэтому анализ антоцианового состава ягод рябины, ирги и жимолости ранее не изученных территорий является важной и актуальной задачей.

В связи с этим цель данной работы - определить и сравнить состав антоцианов рябины черноплодной, ирги овальнолистной и жимолости голубой, произрастающих на территории Красноярского края, методом ВЭЖХ.

\section{Экспериментальная часть}

Поскольку антоцианы окрашены, специфичным для их определения должен оказаться метод спектрофотометрический в видимой области спектра. По данным литературы, в диапазоне длин волн 510-540 нм максимумы поглощения имеют большинство природных антоцианов. Более точное положение максимума для каждого антоциансодержащего объекта индивидуально и зависит от ряда факторов [15].

Исследуемые в данной работе ягоды рябины черноплодной, ирги овальнолистной, жимолости голубой были собраны на территории Енисейского района Красноярского края. Плоды были заморожены. Срок годности для замороженных ягод не более 9 месяцев [16]. В течение этого времени ягоды практически полностью сохраняют вкусовые качества и питательные вещества. Таким образом, использование в производстве замороженных ягод позволяет устранить сезонность их переработки, обусловленную коротким периодом массового сбора, и обеспечить ценным сырьем и витаминами в осеннее-зимний период.

Экстракция проводилась 40\%-ным спиртом, содержащим 1 \% $\mathrm{HCl}$ на кипящей водяной бане в течение 15 минут. Соотношение «сырьё : экстрагент»-1:30. Спектрофотометрическое определение суммы антоцианов в пересчете на цианидин-3-глюкозид выполняли по методике [17].

Спиртовые экстракты плодов рябины, ирги и жимолости по отдельности хроматографировали на жидкостном хроматографе Agilent 1200 при следующих условиях: колонка Luna 5u C18(2) 100A (250x4,6mm5 мкм); температура термостата $25{ }^{\circ} \mathrm{C}$; длина волны детектирования 543 нм; подвижная фаза: ацетонитрил; 0,01\%-ный раствор фосфорной кислоты в воде; режим элюирования градиентный (табл. 1). Сбор данных, обработка хроматограмм и спектров поглощения проводили с помощью программы Agilent ChemStation. Идентификацию пиков

$$
-145-
$$


осуществляли по литературным данным, сопоставляя времена удерживания на аналогичных колонках, и УФ-спектрам индивидуальных компонентов [3, 12, 14, 18-20]. Отдельно фиксировали растворы стандартного образца цианидин-3-глюкозида с разной концентрацией и строили градуировочный график. Установлено, что предел количественного обнаружения цианидина3-глюкозида 0,01 мкг/мл (при соотношении сигнал/шум 1:5). Электронные спектры в УФ- и видимой области спектра фиксировали на спектрофотометре «Shimadzu-1700» в кюветах толщиной 10 мм.

\section{Обсуждение результатов}

На спектрофотометре UV1700 «Shimadzu» PharmaSpec были сняты спектры поглощения спиртового экстракта жимолости, рябины черноплодной и ирги (рис. 1). Полученные кривые поглощения спиртовых экстрактов имеют два характерных максимума поглощения в УФ ( $281 \pm 2$ нм) и в видимой области ( $543 \pm 2$ нм).

Таблица 1. Режим элюирования

\begin{tabular}{|c|c|}
\hline Время, мин & Содержание ацетонитрила, об. \% \\
\hline $0-10$ & $1-15$ \\
\hline $10-35$ & $15-25$ \\
\hline $35-40$ & $25-1$ \\
\hline
\end{tabular}

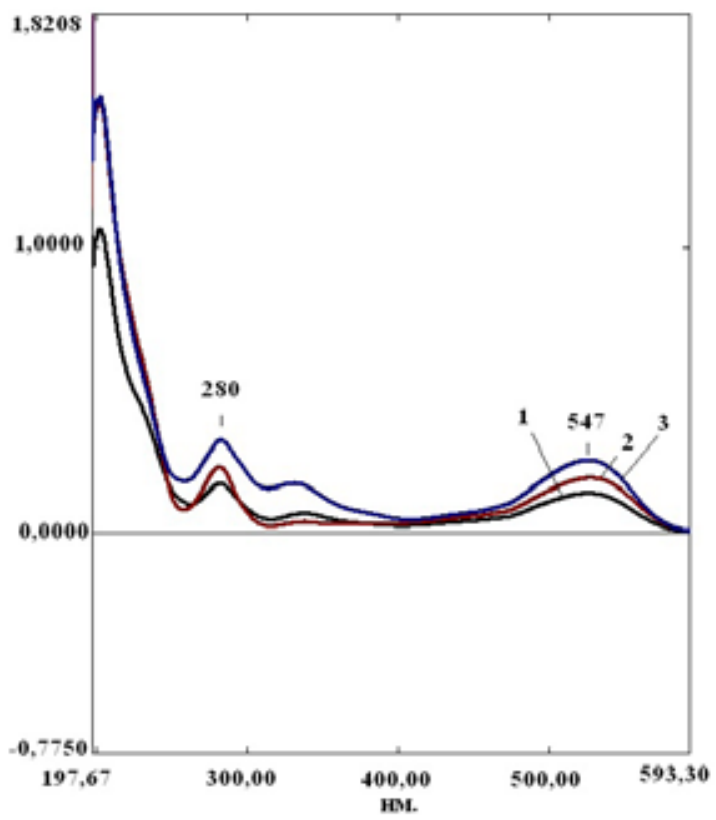

Рис. 1. Спектры поглощения экстракта жимолости в 40\%-ным этиловым спиртом, содержащем $1 \%$ $\mathrm{HCl}$ (1), экстракта рябины черноплодной (2) и экстракта ирги Красноярского края в аналогичном растворителе (3) 
Таблица 2. Сумма антоцианов в плодах жимолости, ирги и рябины черноплодной

\begin{tabular}{|c|c|}
\hline Название ягоды & Содержание, мг/100 г свежих плодов \\
\hline Ирга овальнолистная & 210 \\
\hline Рябина черноплодная & 150 \\
\hline Жимолость голубая & 107 \\
\hline
\end{tabular}



Рис. 2. Хроматограмма антоцианов плодов рябины черноплодной

В табл. 2 приведены результаты количественного определения суммы антоцианов в пересчете на Cyn-3-Glu, полученные спектрофотометрическим методом. Наибольшее суммарное количество антоцианов обнаружено в ирге овальнолистной, что не противоречит литературным данным [12]. Наименьшее - в жимолости голубой (107 мг/ 100 г), это меньше, чем в жимолости, выращенной в условиях Белгородской области (содержание от 130-450 мг/100 г свежих плодов) [14].

В экстракте рябины черноплодной Красноярского края обнаружено шесть компонентов (рис. 2), представляющих собой антоцианы, четыре из них идентифицированы (табл. 3). Антоцианы с наибольшим процентным содержанием - цианидин-3-галактозид (51 \%), цианидин-3арабинозид (25\%), пеонидин-3-глюкозид (19\%).

В экстракте ирги овальнолистной Красноярского края обнаружено пять компонентов (рис. 3), представляющих собой антоцианы, четыре из них идентифицированы (табл. 4). Антоцианы с наибольшим процентным содержанием: цианидин-3-галактозид (59 \%), цианидин-3глюкозид (24 \%). Пик № 5 соответствует спектру, представленному на рис. 4. Данный спектр отличается от спектров, которые присущи антоцианам, характерен для фенолкарбоновых кислот, но при отсутствии стандартного образца идентифицировать его не удалось. 
Таблица 3. Антоцианы в плодах рябины черноплодной Красноярского края

\begin{tabular}{|c|c|c|c|c|}
\hline $\begin{array}{c}\text { Номер } \\
\Pi / \Pi\end{array}$ & $\operatorname{Tr}$ & Название & Спектр & $\begin{array}{c}\text { Процент } \\
\text { от суммарного } \\
\text { содержания } \\
\text { антоцианов }\end{array}$ \\
\hline 1 & 18,652 & Не идентифицирован* & (1) & 0,6 \\
\hline 2 & 21,307 & Cyn-3-gal & $=$ & 51 \\
\hline 3 & 21,935 & Cyn-3-glu & if & 1,9 \\
\hline 4 & 23,176 & Cyn-3-ara & (1) & 25 \\
\hline 5 & 25,703 & Не идентифицирован & (4) & 2,5 \\
\hline 6 & 30,051 & Peo-3-glu & (1) & 19 \\
\hline
\end{tabular}

*При отсутствии стандартных образцов однозначная идентификация затруднена. 




Рис. 3. Хроматограмма антоцианов плодов ирги овальнолистной

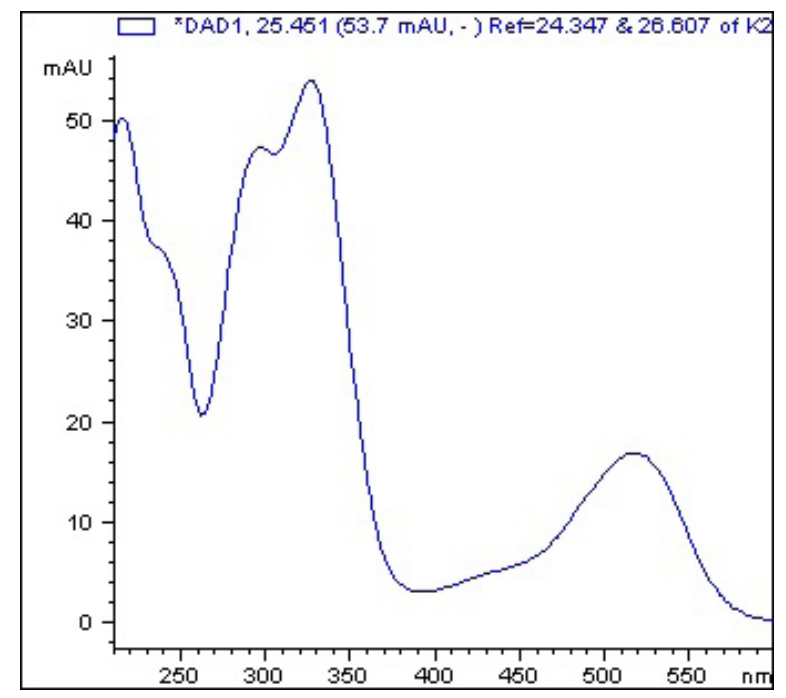

Рис. 4. Спектр поглощения пика № 5

В экстракте жимолости голубой Красноярского края обнаружено четыре компонента (рис. 5), представляющие собой антоцианы, три из них идентифицированы (табл. 3). Антоциан с наибольшим процентным содержанием - цианидин-3-глюкозид (92 \%).

Таким образом, полученные данные свидетельствуют о том, что антоциановый состав трёх ягод отличается как качественно, так и количественно. Во всех ягодах присутствует цианидин3-глюкозид и пеонидин-3-глюкозид. Соотношение данных антоцианов по процентному содержанию к суммарному содержанию антоцианов в ягодах иллюстрирует рис. 6 . Видно, что больше всего цианидина-3-арабинозида и пеонидина-3-глюкозида содержится в рябине черноплодной, цианидина-3-глюкозида - в жимолости, цианидина-3-галактозида - в ирге. На рис. 7 представлена хроматограмма смеси экстрактов всех трёх ягод. При перемешивании данных экстрактов количественное содержание отдельных антоцианов суммируется. Исходя из выше- 
Таблица 4. Антоцианы в плодах ирги овальнолистной Красноярского края



*При отсутствии стандартных образцов однозначная идентификация затруднена. 
Таблица 5. Антоцианы в плодах жимолости голубой Красноярского края

\begin{tabular}{|c|c|c|c|c|}
\hline $\begin{array}{c}\text { Номер } \\
\text { п/п }\end{array}$ & $\operatorname{Tr}$ & Название & Спектр & $\begin{array}{c}\text { Процент от суммарного } \\
\text { содержания } \\
\text { антоцианов }\end{array}$ \\
\hline 1 & 19,420 & Cyn- 3,5-diglu & . & 2 \\
\hline 2 & 21,897 & Cyn-3-glu & (1) & 92 \\
\hline 3 & 24,753 & не идентифицирован & (1) & 4 \\
\hline 4 & 29,788 & Peo-3-glu & (1) & 2 \\
\hline
\end{tabular}

*При отсутствии стандартных образцов однозначная идентификация затруднена.

сказанного, можно рекомендовать данные ягоды в качестве сырья для получения отдельных антоцианов, смесь экстрактов этих ягод - как источник веществ - «свидетелей» - цианидина3-галактозида, цианидина-3-глюкозида, цианидина-3-арабинозида, пеонидина-3-глюкозида для идентификации антоцианов в сложных смесях.

\section{Выводы}

1. Методом ВЭЖХ с использованием УФ-детектора определён антоциановый состав ягод рябины черноплодной, жимолости голубой и ирги овальнолистной, произрастающих на территории Красноярского края. Определено количественное содержание каждого компонента. 


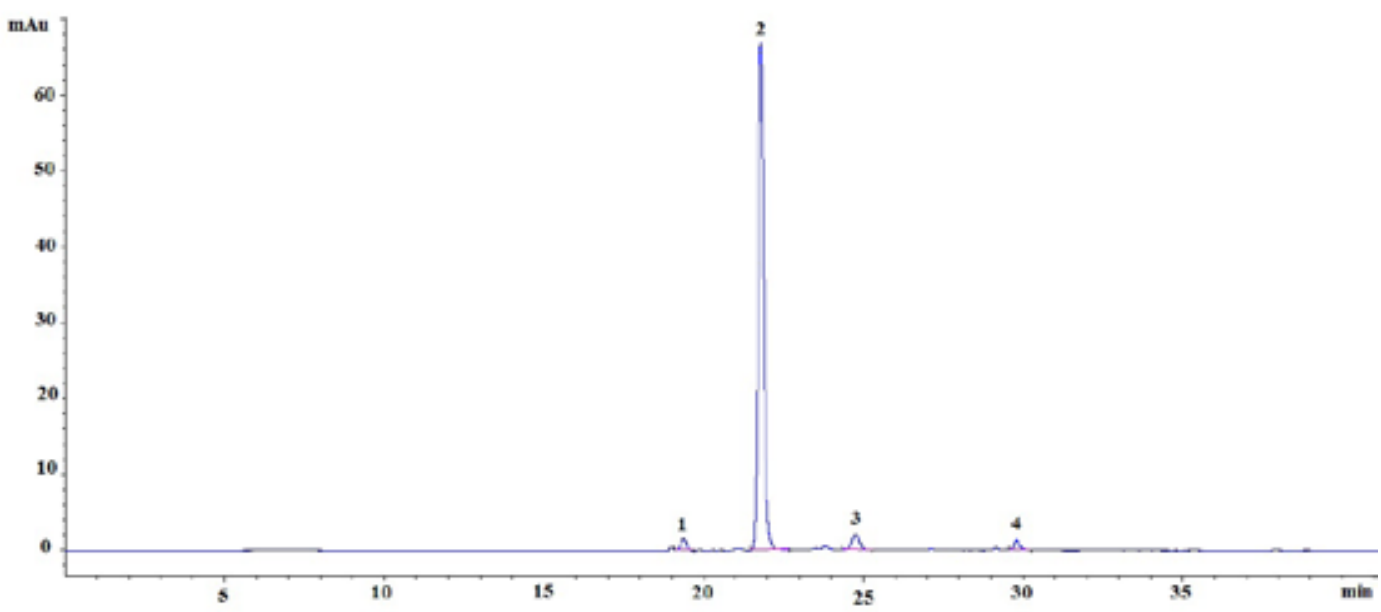

Рис. 5. Хроматограмма антоцианов жимолости голубой

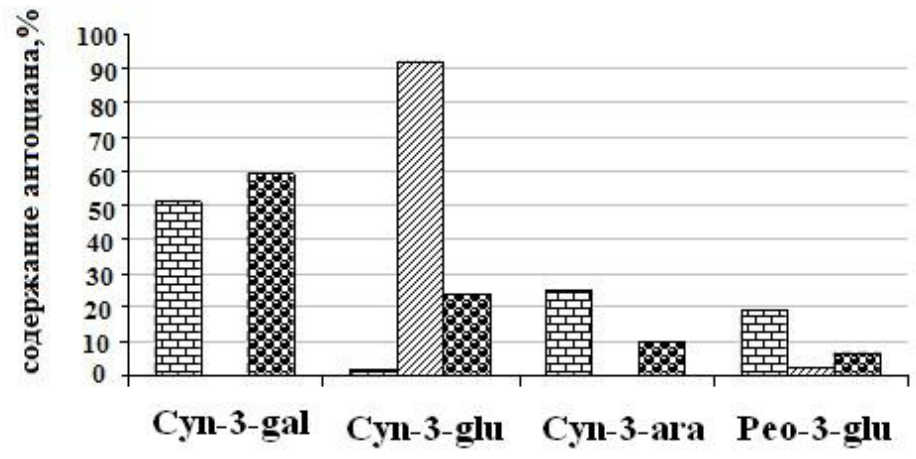

园 Рябина

черноплодная

У Жимолость

Ирга

Рис. 6. Процентное содержание антоцианов в ягодах Красноярского края

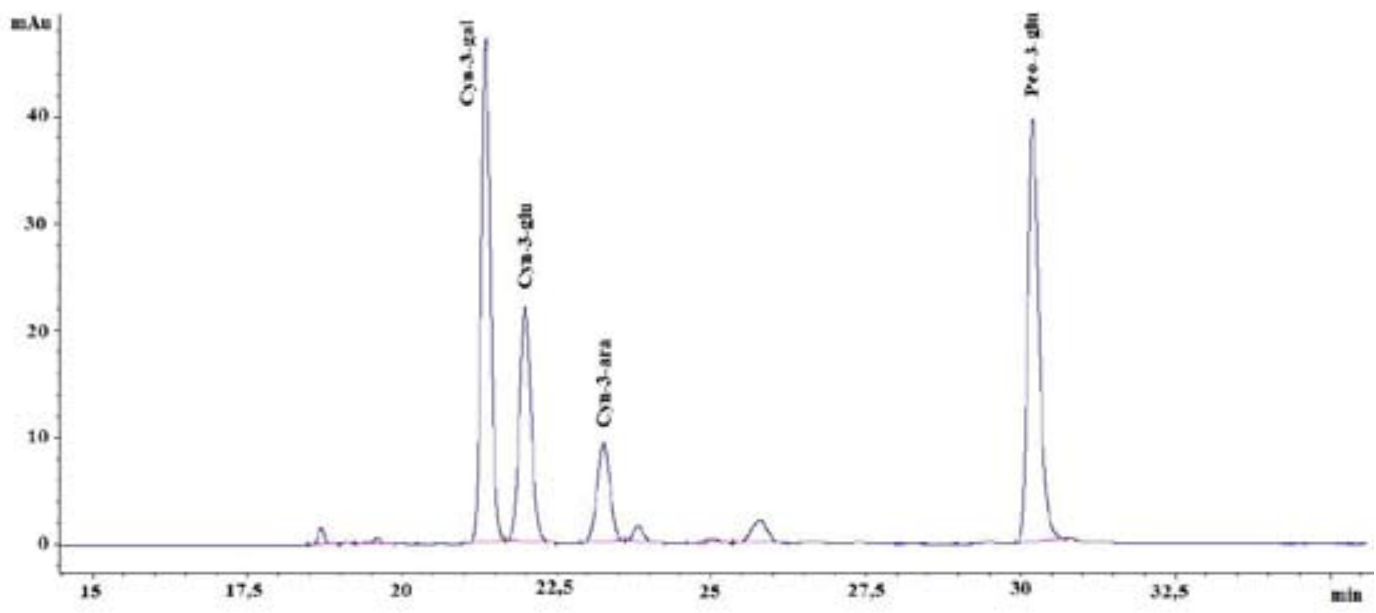

Рис. 7. Хроматограмма смеси рябины черноплодной, ирги и жимолости 
2. Установлены основные различия в антоциановом составе рябины черноплодной, жимолости голубой и ирги овальнолистной Красноярского края.

\section{Список литературы}

1. Охрименко Л.П., Калинкина Г.И., Дмитрук С.Е. Сравнительное исследование толокнянки, брусники и близких к ним видов, произрастающих в республике Саха(Якутия) // Химия растительного сырья 2005. № 1. C. 31-35. [Ohrimenko L.P., Kalinkin G.I., Dzmitruk S.E. Comparative study of bearberry, cranberries and similar species growing in the Republic of Sakha (Yakutia) // Chemistry of plant raw material 2005. Vol. 1. P. 31-35. (In Russ.)]

2. Макаревич А.М., Шутова А.Г., Спиридович Е.В., Решетников В.Н. Функции и свойства антоцианов растительного сырья. Труды БГУ 2010. Т.4. вып. 2, С. 1-11. [ Makarevich А. М., Shutova A.G., Spiridovich E.V., Reshetnikov V.N. Functions and properties of anthocyanins vegetable raw materials. Proceedings of the Belarusian State University 2010. Vol. 4(2). P.1-11. (In Russ.)]

3. Bornsek S. M. Bioefficacy of anthocyanins from bilberries (Vaccinium myrtillus L.). Doctoral Dissertation. Ljubljana: 2012. Р. 131.

4. Крупенникова В.Г., Федосеева Г.М. Антоцианы скабинозы венечной // Сибирский медицинский журнал. 2008. № 2. C.78-80. [Krupennikova V.G., Fedoseyeva G. M. Anthocyanins of skabinozy coronary. Siberian journal of medicine 2008. Vol 2. P.78-80. (In Russ.)].

5. Дайнека В.И., Григорьев А.М. Определение антоцианов методом высокоэффективной жидкостной хроматографии. Некоторые закономерности удерживания // Журнал аналитической химии 2004. T. 59. № 3. C. 305-309. [ Daineka V. I., Grigoriev A. M. Definition of anthocyanin HPLC. Some patterns of retention. Journal of Analytical Chemistry 2004. Vol. 59(3). P. 305-309. (In Russ.)]

6. Brezhneva T.A., Logvinova E.E., Slivkin A.I., Tarabrina V.N. Spectral characteristics of compounds of fruit. Proceedigs of Voronezh state University. Series of Physiological, Biochemical and Molecular Biology Sciences. 2013. Vol. 2. P. 169-172.

7. Путырский И.Н., Прохоров В. Н. Универсальная энциклопедия лекарственных растений. M.: Махаон, 2000. 654 c.[Putyrskaya I. N.. Prokhorov V. N. Universal Encyclopaedia of medicinal plants. Moscow: Mahaon, 2000. 654 p.(In Russ.)]

8. Nakajima J., Tanaka I., Seo S., Yamazaki M., Saito K. LC/ PDA/ESI-MS Profilin gandradical Scavenging Activity of Anthocyanins in various berries. Journal of biomedicine and biotechnolody 2004. Vol 5. P. 241-247.

9. Ding M., Feng R., Wang S.Y., Bowman L., Lu Y., Qian Y., Castranova V., Jiang B.H, Shi $\mathrm{X}$. Cyanidin-3-glucoside, a natural product derived from blackberry, exhibits chemo preventive and chemotherapeutic activity. J. Biol. Chem. 2006. Vol. 281. P. 17359-17368.

10. Петрова В.П. Дикорастущие плоды и ягоды. М.: Лесн. пром-сть, 1987. 248 с. [ Petrova V.P. Wild fruits and berries. Moscow: Lesn.prom-st, 1987. 248 p. (In Russ.)]

11. Петрова В.П. Биохимия дикорастущих плодово-ягодных растений. Киев: Вища шк., 1986. 276 с. [Petrova V.P. Biochemistry of wild fruit plants. Kiev: Vishcha sc., 1986. 276 p. (In Russ.)]

12. Степанова А.В., Сорокопудов В.Н., Сорокопудова О.А., Мячикова Н.И., Степанова Д. В. Плоды видов рода Amelanchier Medik как источник антоцианов в условиях Белогорья // Научные ведомости БелГУ. Серия: Медицина. Фармация. 2012. № 10-3(129). [Stepanova A.V., 
Sorokopudov V. N., Sorokopudova O. A., Myachikova N. I., Stepanova D.V. The fruits of the genus Amelanchier Medik as a source of anthocyanins in the conditions of Belogoriya. Scientific statements Belgorod State University. Series: Medicine. Pharmacy 2012. Vol. 10-3 (129). (In Russ.)]

13. Lila M.A. Anthocyanins and Human Health: An In Vitro Investigative Approach. J. Biomed. Biotechnol 2004. Vol. 5. P. 306-313.

14. Чулков А.Н., Гостищев Д.А., Дейнека Л.А., Дейнека В.И., Писарев Д. И. Сорокопудов В.Н., Сазонов С.А. Плоды жимолости синеплодной как источник антоцианов. Химия растительного сырья 2011. № 4. C.173-176. [Chulkov A.N., Gostishchev D.A., Dejneka L.A., Dejneka V.I., Pisarev D.I., Sorokopudov V.N., Sazonov S.A. The fruits of honeysuckle sineplodnoy as a source of anthocyanins. Chemistry of plant raw materials 2011. Vol. 4. P.173-176. (In Russ.)]

15. Timberlake C.F. Anthocyanins - Occurence, Extractionand Chemistry. FoodChem. 1980. Vol. 5. P.69-80.

16. ГОСТ Р 53956-2010. Фрукты быстрозамороженные. Общие технические условия. М.: Стандартинформ, 2011. 20 с. [GOST R 53956-2010. Fruit frozen. General specifications. Moscow: Standartinform, 2011. p. 20. (In Russ.)]

17. Giusti M.M., Wrolstad R.E. Characterization and measurement of Anthocyanins by UV-visible spectroscopy. Cur. Prot. Food Anal. Chem. New York 2001. F1.2.1 - F 1.2.13.

18. Rudakov O.B., Khairutdinova A.D., Odin A.P., Bolotov V.M. Fractional composition of anthocyan dyes from vegetative extractes and its control by the mrthod of HPLC. Proceedigs of Voronezh state University. Series of Chemistry. Biology. Pharmacy. 2004. № 1. P. 85-93. (In Russ.)]

19. Чулков А.Н., Дейнека В.И., Дейнека Л.А., Степанова А.В., Сорокопудов В.Н. Антоцианы плодов шести видов AMELANCHIER SP // Научные ведомости. Серия «Естественные науки» 2011. № 9(104). Вып. 15/2. C. 208-214. [Chulkov A. N., Dejneka V. I., Dejneka L. A., Stepanova A. V., Sorokopudov V. N. Anthocyanins of six species of AMELANCHIER fruits. Scientific Gazette, Series Science 2011. Vol9 (104). Issue 15/2. P. 208-214. (In Russ.)]

20. Chaovanalikit A., Thompson M.M. Wrolstad R. E. Characterization and Quantification of Anthocyanins and polyphenolics in blue Honeysuckle (Lonicera caerulea L). J. Agric.Food Chem. 2004. Vol. 52. P. 848-852. 